\title{
Description of a Website Resource for Turbulence Modeling Verification and Validation
}

\author{
Christopher L. Rumsey* \\ NASA Langley Research Center, Hampton, VA 23681-2199 \\ Brian R. Smith ${ }^{\dagger}$ \\ Lockheed Martin Aeronautics Company, Fort Worth, TX 76101 \\ George P. Huang ${ }^{\ddagger}$ \\ Wright State University, Dayton, OH 45435
}

\begin{abstract}
The activities of the Turbulence Model Benchmarking Working Group - which is a subcommittee of the American Institute of Aeronautics and Astronautics (AIAA) Fluid Dynamics Technical Committee - are described. The group's main purpose is to establish a web-based repository for Reynolds-averaged Navier-Stokes turbulence model documentation, including verification and validation cases. This turbulence modeling resource has been established based on feedback from a survey on what is needed to achieve consistency and repeatability in turbulence model implementation and usage, and to document and disseminate information on new turbulence models or improvements to existing models. The various components of the website are described in detail: description of turbulence models, turbulence model readiness rating system, verification cases, validation cases, validation databases, and turbulence manufactured solutions. An outline of future plans of the working group is also provided.
\end{abstract}

\section{Introduction}

The Turbulence Model Benchmarking Working Group, hereafter referred to as the TMBWG, is a committee formed in 2008-2009 under the auspices of the AIAA Fluid Dynamics Technical Committee. The members of the group have interests in turbulence model development, implementation, application, verification/validation, and uncertainty. Here, verification means establishing the correctness of the code in representing the intended model equations (done by systematic discretization convergence tests); validation means establishing the validity of a model via comparison with experiment from the perspective of intended uses of the model. ${ }^{1}$ Members of the TMBWG come from both the AIAA Fluid Dynamics Technical Committee and the outside research community. The group has determined that a repository for turbulence model documentation - including verification and validation cases - would be useful to the CFD community. This resource is envisioned to help the aerospace CFD community achieve consistency and repeatability in turbulence model implementation and usage.

Early in the life of the TMBWG, surveys were conducted of its members as well as of others in the CFD community, regarding the use of turbulence models in Reynolds-averaged Navier-Stokes (RANS) codes. Summaries of the results are given in the Appendix. For the most part, the survey results were not surprising. Four key points were: (a) existing turbulence models were felt to be reasonably accurate for simple flows, but not for complex flows; (b) there is generally low confidence that consistent results will be obtained when a given model is implemented in multiple codes; (c) even with advances in large-eddy simulation methods, the need for RANS turbulence modeling will likely persist for many years; and (d) improved model documentation and benchmarking are needed to help improve consistency between codes as well as to aid in the verification and validation process.

Predicting if and when breakthroughs in RANS turbulence models may be made in the future is impossible, but having a receptive environment for new ideas can help encourage innovation. The committee felt that by making improvements in turbulence modeling documentation as well as by providing a set of consistent benchmark cases, a forum could be established through which new model ideas could be quickly tested and accepted into the CFD

\footnotetext{
* Senior Research Scientist, Computational AeroSciences Branch, Mail Stop 128, Associate Fellow AIAA.

$\dagger^{\dagger}$ Lockheed Martin Fellow for Aeronautics and CFD, Associate Fellow AIAA.

${ }^{\ddagger}$ Professor and Chair, Department of Mechanical and Materials Engineering, Associate Fellow AIAA
} 
community. Also, such a forum would help establish greater consistency among those using existing turbulence models.

A website entitled "Turbulence Modeling Resource" was created to help serve this purpose. Its location on the world wide web is http://turbmodels.larc.nasa.gov. The site provides a central location where RANS turbulence models are documented. ${ }^{2}$ The objective is to provide a resource for CFD developers to (a) obtain accurate and up-to-date information on widely-used RANS turbulence models; and (b) verify that models are implemented correctly. This latter capability is made possible through verification cases. The site provides simple test cases and families of grids, along with sample results (including grid convergence studies) from one or more previously verified codes for some of the turbulence models. Furthermore, by listing various published variants of models, the site establishes naming conventions in order to help avoid confusion when comparing results from different codes.

The site should also help CFD code users to understand and compare the predictions of a variety of models on the fundamental flow problems in the validation database. Note that it is not the intent of this effort to validate turbulence models for a wide range of complex flows over diverse applications. While this would undoubtedly be valuable, it is beyond the scope of what can be supported. Instead, the goal is to provide a set of test cases that illustrate the performance of models for flows that capture fundamental phenomena, in order to establish a consistent basis of comparison as a starting point from which a more thorough validation effort can be conducted for flows of specific interest to users and developers.

There have been many efforts in technical papers in the past to provide validation for turbulence models. For example, Bardina et al. $^{3}$ applied $k-\varepsilon$, Wilcox $k-\omega$, Menter $k-\omega$ SST, and Spalart-Allmaras models to a wide range of simple free-shear and wall-bounded flows, and Marvin and Huang ${ }^{4}$ led an effort to define a set of standard validation and solution data for a variety of flows. There are also many websites today that provide extensive validation information for turbulent flow cases. For example, the CFD-Online website ${ }^{\mathrm{a}}$, the NPARC Alliance website ${ }^{\mathrm{b}}$, and the ERCOFTAC database website ${ }^{\mathrm{c}}$ all provide validation data and CFD results. What makes the current website unique is that it focuses on providing ready access to equations, grids, and flow solution details from previously verified codes as an aid to users who wish to verify their own implementations of models on relatively simple cases.

This website is similar in many ways to an unrealized project envisioned by Marvin and Huang ${ }^{4}$ about 15 years ago, in which a web-based turbulence modeling "living" expert workbench would be essentially an intelligent database and code validation system. The system was envisioned to contain experimental data, model descriptions, model solution algorithms, computer codes, standard model solutions and detailed model comparisons with the data. Not only was it to provide a database for engineers to select the most suitable turbulence models for their applications, but also to act as a convenient medium in which engineers, modelers, and experimentalists could communicate and interact.

Although the current website is not as broad in scope as this earlier idea, it is hoped that it will still serve as a mechanism for fruitful interchange between researchers, leading to greater consistency among the same models in different codes, and encouraging new turbulence modeling ideas.

\section{Turbulence Modeling Resource Website}

Here, the main aspects of the Turbulence Modeling Resource website are described as they currently exist. Because the website is a "living document," many of these aspects will no doubt evolve or expand over time.

\section{A. Description of Turbulence Models}

Currently, five turbulence models are listed in detail on the website, along with their known published variants. These are briefly summarized in Table 1 . The primary references for these models are refs. $5-10$. References for the listed variants can be found on the website. In this paper and on the website, the turbulence models are referred to by the model names in the table.

\section{B. Turbulence Model Readiness Rating System}

The model readiness rating system categorizes the "readiness" of models so that developers and users can assess the maturity of a given model when determining whether to implement and test it for their own specific applications. This system does not judge the quality or capability of turbulence models. Instead, it is intended to provide information

\footnotetext{
${ }^{a}$ http://www.cfd-online.com/Wiki/Validation_and_test_cases, cited: 6/1/2010.

${ }^{b}$ http://www.grc.nasa.gov/WWW/wind/valid/archive.html, cited: 6/1/2010.

${ }^{c}$ http://cfd.mace.manchester.ac.uk/ercoftac, cited: 6/1/2010.
} 
Table 1. Summary of turbulence models described at http://turbmodels.larc.nasa.gov (cited: 4/19/2010)

\begin{tabular}{|c|c|c|}
\hline Generic Name & Model Name & Feature \\
\hline Spalart-Allmaras 1-eqn & $\begin{array}{l}\text { SA } \\
\text { SA-Ia } \\
\text { SA-noft2 } \\
\text { SA-RC } \\
\text { SA-Catris } \\
\text { SA-Edwards } \\
\text { SA-fv3 } \\
\text { SA-salsa } \\
\text { SA-comp } \\
\text { SA-rough }\end{array}$ & $\begin{array}{l}\text { standard published version } \\
\text { standard version with trip term } \\
\text { standard version without } f_{t 2} \text { term } \\
\text { rotation \& curvature version } \\
\text { compressible version } \\
\text { Edwards-modified version } \\
\text { unofficial version (discouraged) } \\
\text { extended for nonequilibrium flows } \\
\text { modified for compressible mixing layers } \\
\text { rough wall version }\end{array}$ \\
\hline Menter $k$ - $\omega$ SST 2-eqn & $\begin{array}{l}\text { SST } \\
\text { SST-V } \\
\text { SST-2003 } \\
\text { SST-sust } \\
\text { SST-Vsust }\end{array}$ & $\begin{array}{l}\text { standard original published version } \\
\text { standard version with vorticity production } \\
\text { slightly modified version from } 2003 \\
\text { version with sustaining terms } \\
\text { sustaining terms \& vorticity production }\end{array}$ \\
\hline Wilcox & $\begin{array}{l}\text { Wilcox2006 } \\
\text { Wilcox } 2006-\mathrm{V} \\
\text { Wilcox } 1998 \\
\text { Wilcox1998-V } \\
\text { Wilcox1988 } \\
\text { Wilcox1988-V }\end{array}$ & $\begin{array}{l}2006 \text { version } \\
2006 \text { version with vorticity production } \\
1998 \text { version } \\
1998 \text { version with vorticity production } \\
1988 \text { version } \\
1988 \text { version with vorticity production }\end{array}$ \\
\hline $\begin{array}{l}\text { Explicit Algebraic Stress } k-\omega \\
2 \text {-eqn }\end{array}$ & $\begin{array}{l}\text { EASMko2003 } \\
\text { EASMko2003-S } \\
\text { EASMko2001 } \\
\text { EASMko2001-S } \\
\text { EARSMko2005 } \\
\text { EARSMko2005-CC } \\
\text { EARSMko2005a } \\
\text { EARSMko2005a-CC }\end{array}$ & $\begin{array}{l}2003 \text { version from NASA } \\
2003 \text { version with approx strain production } \\
2001 \text { version (different } \sigma_{k} \text { and } \gamma \text { ) } \\
2001 \text { version with approx strain production } \\
2005 \text { version from HUT } \\
2005 \text { version with curvature correction } \\
2005 \text { version with improvement for 3-D } \\
2005 \text { w curvature \& improvement for 3-D }\end{array}$ \\
\hline Shur et al. 1-eqn & $\begin{array}{l}\text { Nut-92 } \\
\text { Nut-92-FD }\end{array}$ & $\begin{array}{l}\text { official version } \\
\text { earlier version (different for rough walls) }\end{array}$ \\
\hline
\end{tabular}


to the end user regarding how "well-defined," "well-used," and "well tested" a model is. A model that has been implemented and used in multiple codes and by multiple people will receive a higher rating than a model that has only been implemented and used in a single code. Furthermore, an attempt is made with this rating system to insure that the same model version in multiple codes will yield the same results.

The rating system is delineated in Table 2. To date, the models on the website have not yet been rated according to this proposed rating system. The committee is allowing time for the turbulence modeling community to comment on the proposal first.

Note that the minimum level (Level 0) indicates that a model is well-described in a referenceable publication and has a sponsor. This level carries no negative connotations; it simply means that the model in question has not been widely tested or sufficiently verified beyond the original reference. A sponsor performs the tasks required for a model to progress through the rating system: running cases and reporting results as necessary, and working with the committee and page curator to meet any requirements needed to list the model on the website. Also note that the phrase "verification cases" is rather loosely defined here to indicate cases for which a thorough grid refinement study has been conducted, so as to unambiguously establish the grid-converged result when using the model. Such cases are important because others can subsequently test their implementation of the same model by seeing if their results for the verification cases approach the same solutions as the grid is refined.

Most widely-used turbulence models today are probably at Level 1 or Level 2. Even when a given model is implemented in more than one code, results often do not agree as the grid is refined. This inter-code consistency has yet to be demonstrated for most models, and limits the rating to Level 1. With Level 3, independent coding (to insure that a given coder/modeler does not make the same error when implementing in different codes) and some level of independent verification is required (in other words, the same person should not be performing all tests).

Table 2. Turbulence Model Rating System

\begin{tabular}{l|llll}
\hline Description & Level 0 & Level 1 & Level 2 & Level 3 \\
\hline Sponsor exists for the turbulence model & required & required & required & required \\
\hline Model completely described and referenceable & required & required & required & required \\
\hline Model in at least 1 CFD code & & required & required & required \\
\hline Model run on flat plate with grid study & & required & required & required \\
\hline Model in two or more codes, results agree & & & required & required \\
\hline Model run on 2 or more verification cases & & & required & required \\
\hline Model in code outside home organization & & & & required \\
\hline Results independently obtained/verified & & & & required \\
\hline
\end{tabular}

\section{Verification Cases}

The purpose of the verification part of the website is to provide a large sequence of nested grids of the same family, along with results from existing CFD codes that employ specific forms of particular turbulence models, in order to help programmers verify their implementations of these same models. On a given grid, there may be differences between the results from different codes, but presumably as the grid is refined the results should approach the same answer (if the flow conditions and boundary conditions are the same). With verification, the purpose is not to establish the "goodness" of a model compared to experiment, but rather to establish that a model has been correctly implemented, as intended according to the equations and boundary conditions. (It is through validation that a model's "goodness" is established.) Therefore, computed results and experiment are not compared in this procedure.

To date, four turbulence model verification cases have been included on the website. These are: 2-D zero pressure gradient flat plate, 2-D planar shear, 2-D bump-in-channel, and 3-D bump-in-channel. These particular cases were purposefully chosen to be very simple. For example, none of the cases has any separated flow regions. As a result, these cases are also relatively easy to converge iteratively to near machine zero, which is important when trying to establish grid convergence characteristics. A number of details about the verification cases are also described in Rumsey. ${ }^{2}$ Here, only one example is given.

Although conceptually very simple, the 2-D bump-in-channel case involves wall curvature and, as a result, pressure gradients. It was run at essentially incompressible conditions: $M=0.2$, at a Reynolds number of $\operatorname{Re}=3$ million 
based on unit length of the grid. The lower wall is a viscous-wall bump extending from $x=0$ to 1.5 (the actual bump itself - i.e., non-zero $y$ - is from $x=0.3-1.2$ ). The maximum bump height is $y=0.05$. The definition of the bump is:

$$
\begin{array}{lll}
y & =0 \quad 0 \leq x<0.3 \quad \text { and } & 1.2<x \leq 1.5 \\
y & =0.05\left[\sin \left(\frac{\pi x}{0.9}-\frac{\pi}{3}\right)\right]^{4} & 0.3 \leq x \leq 1.2
\end{array}
$$

The upstream and downstream farfield extends 25 units from the viscous-wall, with symmetry plane boundary conditions imposed on the lower wall between the farfield and the solid wall. The upper boundary is located a distance of $y=5.0$ above the bump. It is taken to be a symmetry plane. Figs. 1(a) and (b) show the layout of this case, along with the boundary conditions.

Some results using SA are shown in Figs. 2(a)-(c), and results using SST-V are shown in Figs. 3(a)-(c). The two CFD codes - structured code CFL3D ${ }^{11}$ and unstructured code FUN3D ${ }^{12}$ - approach nearly identical results as the grid is refined ( $h \rightarrow 0$, where $h$ represents a measure of the mean grid spacing $\sqrt{1 / N}$, with $N$ the number of grid points). With two different independent codes yielding the same results on a sufficiently fine grid, one can more confidently assert that the models have been implemented correctly. Many detailed results from these two codes are provided on the website for this case, including the field variables eddy viscosity for SA, and eddy viscosity, $k$, and $\omega$ for SST-V.

\section{Validation Cases}

A large percentage of industry respondents of the industry survey (see Appendix) felt that the emphasis of benchmarking efforts should be placed on complex flows. The working group discussed this issue extensively, but decided to focus only on several relatively simple flows for the purposes of the website. With simple flows, it is easier to ensure grid converged solutions, easier for multiple codes to be employed on the same problem, and often easier to find reliable and well-documented experiments. With complex flows (such as 3-D, large separations, etc.), one is usually not sure whether disagreement with experiment is caused by the turbulence model or some other factor. See, for example, the discussion in section 1.1 of Rumsey et al. ${ }^{13}$

The working group has decided to include five validation cases on the website. Three of these are still in the process of being evaluated, so are listed as tentative:

- 2-D incompressible zero pressure gradient flat plate pl-16 $^{14}$

- 2-D incompressible NACA 0012 airfoil $^{17-19}$

- 2-D incompressible planar shear ${ }^{20}$ (tentative)

- Axisymmetric incompressible adverse pressure gradient separated flow ${ }^{21}$ (tentative)

- 2-D compressible supersonic zero pressure gradient flat plate (tentative) $^{22}$

Theory and data have been posted to the website for the first two of these cases, and initial efforts have been made toward obtaining CFD results for certain turbulence models using multiple codes. Some of these results are described here.

\section{2-D Incompressible Zero Pressure Gradient Flat Plate}

For the flat plate, the validation case is the same as the verification case. The flow conditions are $M=0.2, \operatorname{Re}=10$ million based on the full length of the plate $(L=2)$, or $\mathrm{Re}=5$ million per unit length. Grid sizes ranged all the way from the finest $545 \times 385$ to the coarsest $35 \times 25$, and all were members of the same grid family, achieved by removing every other point in each coordinate direction for each coarser grid level. The finest grid had a wall normal spacing of $y=5 \times 10^{-7}$, yielding an average $y^{+}$of approximately 0.1 over the plate.

At the present time, results have been obtained using two models - SA and SST-V - with the two codes CFL3D and FUN3D. The CFD computations are compared against the Karman-Schoenherr formula ${ }^{14}$ for skin friction as a function of $R e_{\theta}$ in Fig. 4(a), and the velocity profiles based on wall variables from Coles ${ }^{15}$ at $R e_{\theta}=10,000$ in Fig. 4(b). The comparisons are made using $R e_{\theta}$ as opposed to an absolute $x$-location on the plate in order to avoid issues with transitional flow behavior of different models at the leading edge of the plate. 
It should be noted that computing $R e_{\theta}$ typically involves an additional post-processing step for many CFD codes (numerically integrating to obtain the momentum thickness $\theta$ ). Although this step is relatively straightforward for the flat plate, nonetheless some numerical errors are unavoidably introduced which may vary depending on the postprocessing program employed. When viewing comparisons, this additional potential source of error should be taken into consideration.

Results were indistinguishable on the finest $545 \times 385$ grid for the two codes CFL3D and FUN3D, so only results from CFL3D on that grid are shown. Both turbulence models yielded $C_{f}$ levels that are between about 1 and $4 \%$ low compared to the Karman-Schoenherr formula in the range of $4000<R e_{\theta}<13000$ (the error is smallest toward the high end of the $R e_{\theta}$ range). However, both fell within the band (shown as the shaded region in Fig. 4(a)) defined by an array of different correlations (see White ${ }^{16}$ ). The velocity profiles are in very good agreement with theory in terms of wall variables, with the biggest differences between the two models occurring near the knee at the bottom end of the log layer.

\section{2-D Incompressible NACA 0012 Airfoil}

For the NACA 0012 airfoil validation case, the conditions are $M=0.15, \operatorname{Re}=6$ million per chord. The definition of the NACA 0012 airfoil is slightly altered so that the airfoil closes with a sharp trailing edge at a chord length of 1 . To do this, the exact NACA 0012 formula is used, then the airfoil is scaled down by 0.99114864 . The scaled formula can be written:

$$
\begin{gathered}
y= \pm 0.594689181\left(0.298222773 \sqrt{x}-0.127125232 x-0.357907906 x^{2}\right. \\
\left.+0.291984971 x^{3}-0.105174696 x^{4}\right)
\end{gathered}
$$

To minimize issues associated with the effect of the farfield boundary (which can particularly influence drag and lift levels at high lift conditions), grids have been provided with the farfield boundary located approximately 500 chords away from the airfoil. Otherwise, a "farfield point vortex" boundary condition correction should be employed. ${ }^{23}$ The effect of farfield extent on drag coefficient is shown in Fig. 5(a), for an angle of attack of $15^{\circ}$, both without and with a farfield point vortex correction. Using an extent of $30 c$ and no correction, the drag coefficient was more than $4 \%$ too high, whereas using the $30 c$ extent with the correction, the error was only $0.3 \%$. Using a $500 c$ extent, the computation with no correction was also only $0.3 \%$ in error.

Grid sizes for the NACA 0012 ranged from the finest $1793 \times 513$ to the coarsest $113 \times 33$. The finest grid had minimum spacing at the wall of $y=4 \times 10^{-7}$, giving an approximate average $y^{+}$between 0.1 and 0.2 over the airfoil at the Reynolds number run. The grid was stretched in the wall-normal direction, and the clustering was maintained in the wake region. The topology is a so-called "C-grid," with the grid wrapping around the airfoil from the downstream farfield, around the lower surface to the upper, then back to the downstream farfield again; the grid connected to itself in a 1-to-1 fashion in the wake. There were 1025 points on the airfoil surface on the finest grid, and 385 points along the wake from the airfoil trailing edge to the outflow boundary.

The NACA 0012 validation case has been run with several different CFD codes at angles of attack of $0^{\circ}, 10^{\circ}$, and $15^{\circ}$. At these conditions, it was found that the $897 \times 257$ grid size was fine enough to produce reasonably low discretization errors. For example, Fig. 5(b) shows a plot of the lift and drag coefficients vs. mean grid spacing $h$ using CFL3D with SA at $\alpha=15^{\circ}$. As the grid density increases $(h \rightarrow 0)$, the lift increases and the drag decreases. Using error estimating procedures from Celik et al., ${ }^{24}$ on the $897 \times 257$ grid with CFL3D, the lift error is approximately $0.13 \%$, and the drag error is approximately $1.52 \%$ compared to an extrapolated infinite grid size (rate of convergence is approximately second order).

Results from four different CFD codes using SA are shown in Figs. 6 and 7. Three of the codes (CFL3D ${ }^{11}$ of NASA Langley, NTS ${ }^{25}$ of NTS in Russia, and TURNS ${ }^{26}$ of Stanford and University of Maryland) used the same $897 \times 257$ grid, while one code (GGNS ${ }^{27}$ of Boeing) was grid-adaptive. All four codes yielded similar results for $C_{L}$, $C_{D}, C_{p}$, and $C_{f}$, and were also in very good agreement with available experimental data. It is important to note that untripped wind tunnel data in the range of interest here (near $\mathrm{Re}=6$ million) produces a drag that is about $10 \%$ lower (at $\alpha=0^{\circ}$ ) than tripped data. ${ }^{17}$ For comparing with "fully turbulent" CFD computations, it is appropriate to compare with tripped data. Here, we compare the computed forces with tripped data of Ladson ${ }^{18}$ in Fig. 6.

For surface pressures, a significant number of available NACA 0012 experimental data appear to rapidly lose twodimensionality with increasing angle of attack. The best pressure data we have found to date is that of Gregory and O'Reilly, ${ }^{19}$ although it is at a lower Reynolds number of 3 million (believed to have little influence on $C_{p}$ for the range considered). The CFD results are compared to this $C_{p}$ data in the left-hand column of Fig. 7. No experimental data is 
available for $C_{f}$, but the CFD results are compared to each other in the right-hand column of the same figure. Without an experimental baseline, the $C_{f}$ results are not technically part of the validation study, but the results do indicate the level of agreement between different codes.

\section{E. Other Resources on the Website}

In addition to having data, grids, and CFD solutions from multiple codes for the 5 planned validation cases, the website also serves as a repository for the turbulent flow validation databases described in Bradshaw et al. ${ }^{28}$ These databases consist of experimental data and simulation results for a wide variety of cases, with an emphasis on complex (strongly nonequilibrium) flows. The validation data were provided courtesy of P. Bradshaw of Stanford University. Part of the group consists of incompressible and compressible flow cases from the 1980-81 Data Library. ${ }^{29}$ There are also additional data from measurements taken in later years, and some reference computations.

The website also provides some information from a series of turbulence-related Validation and Verification $(\mathrm{V} \& \mathrm{~V})$ workshops held in Lisbon, Portugal, at the Instituto Superior Tecnico (IST). The information includes manufactured solutions for wall-bounded incompressible turbulent flow, courtesy of the workshop organizer L. Eca of IST. FORTRAN files are included and are available for download. Additional details about the three workshops can be found in refs. $30-32$. See also Eca et al. ${ }^{33,34}$ for details on the construction of manufactured solutions for several one- and two-equation eddy-viscosity turbulence models.

\section{Future Plans}

The Turbulence Modeling Resource website continues to be populated and updated by the TMBWG. In the near future, the group would like to expand the number of turbulence models described and referenced on the site. Among those being considered are the $v^{2}-f$ model, ${ }^{35}$ the lag model,${ }^{36}$ the $k-\zeta$ model, ${ }^{37}$ the $k$-l model, ${ }^{38}$ and some form or forms of the $k-\varepsilon$ model. $^{39,40}$ It is anticipated that models on the site will be rated according to the model readiness rating system described earlier. Also in the near term, the TMBWG plans to finish defining the five validation cases, then compute each with at least two different CFD codes. At first, the focus will be on some form(s) of the SpalartAllmaras and Menter $k-\omega$ SST turbulence models, because these two are currently among the most commonly used for aerospace applications. In the longer term, it is hoped that each of the verification and validation cases can also be computed using other turbulence models. It is possible that additional verification or validation cases will be defined if the need arises.

\section{Acknowledgments}

The authors gratefully acknowledge Philippe Spalart and Steve Allmaras of Boeing, Karthik Duraisamy of Stanford, and Misha Strelets of NTS for their generous help computing and supplying NACA 0012 results.

\section{Appendix}

When the TMBWG was first formed, an internal survey was taken of its members regarding RANS turbulence modeling. This survey was subsequently changed into a multiple choice version and was distributed widely to various organizations throughout the CFD community. The purpose of the surveys was to help insure that the TMBWG's activities are relevant to the CFD community. Nine active TMBWG group members responded to the initial survey, and 108 responses were received from the industry survey. Summaries of both surveys are provided below.

\section{Preliminary Internal Survey}

1. Given the developments of LES and DNS methods, how long will RANS turbulence models be in wide use, either alone, or in combination with a hybrid RANS/LES method for aerospace development and design?

- Respondents believed that RANS models will likely be in use for between $20-50$ years.

- RANS models will likely be a critical part of hybrid schemes during this period.

- RANS models will complement LES methods, being used heavily for design and optimization, places where LES methods are too expensive for quick-turnaround design. 
2. How critical is the accuracy of RANS turbulence models to the successful application of CFD in aerospace research, development, and design?

- Most felt importance was case dependent. Accuracy is less critical in some cases because (a) currently we do not have grid-converged solutions for many complex applications, and (b) currently, when CFD is used to determine trends and increments, absolute accuracy is not required.

- Turbulence model accuracy will likely become more important in the future as grid converged solutions become more common.

3. Are RANS turbulence models today sufficiently accurate?

- For attached flows, RANS models are for the most part accurate.

- For separated flows, RANS models are for the most part not sufficiently accurate.

- For many specific flow phenomena, current RANS models are judged to be inaccurate: e.g., high Mach number, high curvature, mixing, scalar transport, and reattachment and recovery region.

4. Recognizing that there are different types of wall functions with different degrees of accuracy, are wall functions a useful complement to a RANS turbulence model today? Do you feel they will continue to be useful 5-15 years in the future?

- Can be very useful in regions of a computation where user wants to account for viscous effects, but flow is relatively benign - for example, test section walls.

- Wall functions help to ensure reasonable results for users who do not carefully control near wall spacing.

- Some respondents felt that their use should be minimized - wall functions introduce needless simplifications and inaccuracies.

- The utility of wall functions is linked to the inaccuracy of near wall region modeling in many turbulence models.

- Wall function accuracy depends on (a) whether streamwise pressure gradients are accounted for, and (b) how they behave in separated flows.

5. Do you believe that it is possible to significantly improve the accuracy of turbulence models for use in a predictive way so that the model is essentially either universally applicable, or is applicable over a relatively broad range of applications (classes such as incompressible flows, compressible flows, or attached flows with small separation bubbles), or is RANS turbulence modeling at a level of maturity where further improvement is difficult to achieve and has minimal impact?

- Progress toward a universally accurate model is unlikely.

- Although major improvements seem unlikely in today's environment, anything is possible.

- Improvements for many specific flows - for example, flows with small separation bubbles and reattachment regions - should be possible.

- Phenomena specific improvements could be incorporated in a general modeling scheme through zonal modeling or automated parameter adjustment.

6. Do you believe that there has been significant improvement in the accuracy of RANS turbulence models typically applied in industry in the past 10 years?

- There has been minimal improvement.

- Last major improvements: SST model and EASM maturation.

- There has been minimal attention paid to the dissipation length scale equation, and this is one area where research could pay dividends.

7. Do you have confidence that when a specific turbulence model is implemented in multiple commercial or readily available government codes that consistent results will be obtained? 
- Mostly, confidence was low, due to (a) coding limiters or tweaks to improve robustness (but which change results), (b) coding errors, (c) incomplete or inconsistent model documentation so multiple versions are in existence, or (d) implementations without consultation or involvement of model developer.

8. Do you feel there is a need for improved documentation and expanded benchmarking of turbulence models?

- Improved documentation is sorely needed, especially to help sort out confusion due to multiple versions of a model.

- It would be particularly useful to have documentation and benchmarking provided and on-line.

9. If you believe there is a need for expanded benchmarking of turbulence models, is there a value in allowing multiple model developers to benchmark models using different CFD flow solvers, or does this effort have to be performed by a limited group of qualified experts to be useful?

- Consensus not reached on this question.

- Having an independent researcher implement and benchmark is ideal, but impractical.

10. What types of flow cases should be the emphasis of a benchmarking effort - simple turbulent flows, or complex flows?

- Consensus not reached on this question.

- Simple test cases are more practical (simplify work for developers, make checking easier, and allow specific phenomena to be isolated).

- User community is typically interested in specific, often complex flows, for which grid convergence can be an issue and it is impractical to run many codes and models.

11. What types of flows present a great challenge to RANS turbulence modeling yet you believe should be possible to predict, but are unable to predict with accuracy today?

- Extensive list generated, including: reattachment and recovery regions, multi-element airfoils, 3-D attached boundary layers, tip/edge vortices, round jet-plane jet anomaly, high compressibility, scalar transport, compressible mixing layers, transitional flow regions, and contained separated flows.

\section{Industry Survey}

For the industry survey, most of the respondents were in an aerospace-related industry (such as fluids engineering, heat transfer, turbomachinery, etc.). But there were representatives from a broad range of industries, including chemical engineering, automotive, environmental, materials, petroleum, wind, noise, fire, blast, pipeline, and thermal protection. Most had a PhD, and over 93\% had at least an MS degree. One third had more than 20 years experience in CFD, with a wide spread in age range (average age was 45). The areas of expertise were widely distributed among the categories of code users, code developers, solver developers, and turbulence modelers. The original survey can be found at the Turbulence Modeling Benchmarks Survey website ${ }^{\mathrm{d}}$.

1. Given the developments of LES and DNS methods, how long will RANS turbulence models continue to be in wide use either alone or in combination with a hybrid RANS/LES method for aerospace development and design?

- $21 \%$ believed it will end in 5-10 years.

- The largest percentage (36\%) believed 10-20 years.

- $22 \%$ believed the end will not come for at least 40 years.

- In general, modelers predicted the longest lifetime for RANS, followed by solver developers, then code developers, then users.

2. How critical is the accuracy of RANS turbulence models to the successful application of CFD in aerospace research, development and design?

\footnotetext{
${ }^{\mathrm{d}}$ http://www.engineering.wright.edu/mme/tmb-survey.phtml, cited: 4/19/2010.
} 
- Majority (68\%) believed it is either very or extremely critical.

- The most critical area is the detailed design stage (as opposed to the preliminary design stage).

3. Are today's RANS turbulence models sufficiently accurate? (various flows listed)

- Most had confidence for simple flows (e.g., wall-bounded flows with mild pressure gradient), but were less confident for complex flows (e.g., significant separation, curvature, shock-boundary layer interaction).

- Overall, most respondents felt they are "somewhat" to "very" accurate.

4. In which areas do you believe the accuracy of RANS turbulence models typically applied in industry have been improved in the past 10 years? (various flows listed)

- The respondents generally felt there have been improvements for simple flows, but less so for complex flows.

5. In which areas do you believe the accuracy of RANS turbulence models can be improved in the next 10 years? (various flows listed)

- It appeared that respondents generally believed the same scale of successes they observed for the simple flows in the past 10 years may apply to complex flows in the next 10 years.

6. Do you believe that it is possible to significantly improve the accuracy of RANS turbulence models so that a model is either universally applicable, or is applicable over a relatively broad range of applications (classes such as incompressible flows, or compressible flows, or attached flows with small separation bubbles), or is RANS turbulence modeling at a level of maturity where further improvement is both difficult and of minimal impact?

- The largest percentage (47\%) felt "some improvement possible" (middle response).

- As a group, modelers were more hopeful than the others.

7. Recognizing that there are different types of wall functions with different degrees of accuracy, are wall functions a useful complement to a RANS turbulence model today and in the next 5-15 years?

- A majority (72\%) believed they are and will continue to be either reasonably, very, or extremely useful.

- As a group, modelers were least favorable toward the use of wall functions.

8. How confident are you that consistent results will be obtained when a specific turbulence model is implemented in multiple commercial or readily available government codes?

- Most (59\%) had either no confidence or were only somewhat confident.

- Among them, those with the lowest confidence tended to be modelers and code developers.

9. How would you assess the level of need for improved documentation and expanded benchmarking of turbulence models?

- Most (77\%) felt there is a significant or critical need.

10. If you believe there is a need for expanded benchmarking of turbulence models, is there a value in allowing multiple model developers to benchmark models using different CFD flow solvers? (The alternative is to assign the benchmarking to a limited group of qualified experts.)

- The largest percentage (50\%) believed benchmarking using different people with different codes is of significant value.

11. What types of flow cases should be the emphasis of a benchmarking effort?

- The largest percentage (39\%) believed the emphasis should be placed on complex flows. 


\section{References}

${ }^{1}$ Standard for Verification and Validation in Computational Fluid Dynamics and Heat Transfer, ASME V\&V 20-2009, The American Society
of Mechanical Engineers, Nov. 2009.
${ }^{2}$ Rumsey, C. L., "Consistency, Verification, and Validation of Turbulence Models for Reynolds-Averaged Navier-Stokes Applications,” ac-
cepted for publication in Proceedings of the Institution of Mechanical Engineers, Part G, Journal of Aerospace Engineering, 2010; see also: Paper
EUCASS2009-7, 3rd European Conference for Aerospace Sciences, Versailles, France, July 6-9, 2009.
${ }^{3}$ Bardina, J. E., Huang, P. G., and Coakley, T. J., "Turbulence Modeling Validation, Testing, and Development," NASA TM 110446, April
1997.
${ }^{4}$ Marvin, J. G. and Huang, G. P., "Turbulence Modeling - Progress and Future Outlook,” NASA TM 110414, August 1996.
${ }^{5}$ Spalart, P. R. and Allmaras, S. R., "A One-Equation Turbulence Model for Aerodynamic Flows," Recherche Aerospatiale, No. 1, 1994, pp.
5 51.
${ }^{6}$ Menter, F. R., "Two-Equation Eddy-Viscosity Turbulence Models for Engineering Applications," AIAA Journal, Vol. 32, No. 8, August 1994, pp. 1598-1605.

${ }^{7}$ Wilcox, D. C., Turbulence Modeling for CFD, 3rd edition, DCW Industries, Inc., La Canada CA, 2006.

${ }^{8}$ Rumsey, C. L. and Gatski, T. B., "Summary of EASM Turbulence Models in CFL3D with Validation Test Cases," NASA/TM-2003-212431, June 2003.

${ }^{9}$ Hellsten, A., "New Advanced k-omega Turbulence Model for High-Lift Aerodynamics," AIAA Journal, Vol. 43, No. 9, 2005 , pp. $1857-1869$.

${ }^{10}$ Shur, M., Strelets, M., Zaikov, L., Gulyaev, A., Kozlov, V., and Secundov, A., "Comparative Numerical Testing of One- and Two-Equation Turbulence Models for Flows with Separation and Reattachment," AIAA Paper 95-0863, January 1995.

${ }^{11}$ Krist, S. L., Biedron, R. T., and Rumsey, C. L., “CFL3D User's Manual (Version 5.0),” NASA TM-1998-208444, June 1998.

${ }^{12}$ Nielsen, E. J. and Anderson, W. K., "Recent Improvements in Aerodynamic Design Optimization On Unstructured Meshes," AIAA Journal, Vol.40, No. 6, 2002, pp. 1155-1163.

${ }^{13}$ Rumsey, C. L., Allison, D. O., Biedron, R. T., Buning, P.G., Gainer, T. G., Morrison, J. H., Rivers, S. M., Mysko, S. J., and Witkowski, D. P., "CFD Sensitivity Analysis of a Modern Civil Transport Near Buffet-Onset Conditions," NASA/TM-2001-211263, December 2001.

${ }^{14}$ Schoenherr, K. E., "Resistances of Flat Surfaces Moving Through a Fluid," Trans. SNAME, Vol. 40, 1932, pp. 279-313.

${ }^{15}$ Coles, D., "The Law of the Wake in the Turbulent Boundary Layer," J. Fluid Mech., Vol. 1, 1956, pp. 191-226.

${ }^{16}$ White, F. M., Viscous Fluid Flow, McGraw-Hill Book Company, New York, 1974

${ }^{17}$ McCroskey, W. J., "A Critical Assessment of Wind Tunnel Results for the NACA 0012 Airfoil," AGARD CP-429, July 1988; also NASA TM 100019, October 1987.

${ }^{18}$ Ladson, C. L., "Effects of Independent Variation of Mach and Reynolds Numbers on the Low-Speed Aerodynamic Characteristics of the NACA 0012 Airfoil Section," NASA TM 4074, October 1988.

${ }^{19}$ Gregory, N. and O'Reilly, C. L., "Low-Speed Aerodynamic Characteristics of NACA 0012 Aerofoil Sections, including the Effects of Upper-Surface Roughness Simulation Hoar Frost,” NASA R\&M 3726, Jan 1970.

${ }^{20}$ Bradbury, L. J. S. and Riley, J., "The Spread of a Turbulent Plane Jet into a Parallel Moving Airstream,” Journal of Fluid Mechanics, Vol. 27, Part 2, 1967, pp. 381-394.

${ }^{21}$ Driver, D. M., "Reynolds Shear Stress Measurements in a Separated Boundary Layer Flow," AIAA Paper 91-1787, June 1991.

${ }^{22}$ Van Driest, E. R., "Problem of Aerodynamic Heating," Aeronautical Engineering Review, Vol. 15, October 1956, pp. $26-41$.

${ }^{23}$ Thomas, J. L. and Salas, M. D., "Far-Field Boundary Conditions for Transonic Lifting Solutions to the Euler Equations," AIAA Journal, Vol. 24, No. 7, 1986, pp. 1074-1080.

${ }^{24}$ Celik, I. B., Ghia, U., Roache, P. J., Freitas, C. J., Coleman, H., and Raad, P. E., "Procedure for Estimation and Reporting of Uncertainty Due to Discretization in CFD Applications," Journal of Fluids Engineering, Vol. 130, July 2008, 078001.

${ }^{25}$ Shur, M., Strelets, M., and Travin, A., "High-Order Implicit Multi-Block Navier-Stokes Code: Ten-Year Experience of Application to RANS/DES/LES/DNS of Turbulence," 7th Symposium on Overset Grids \& Solution Technology, October 5-7, 2004, Huntington Beach, CA, USA.

${ }^{26}$ Duraisamy, K., "Studies in Tip Vortex Formation, Evolution and Control," PhD Thesis, Department of Aerospace Engineering, University of Maryland, 2005.

${ }^{27}$ Venkatakrishnan, V., Allmaras, S. R., Kamenetskii, D., and Johnson, F. T., "Higher Order Schemes for the Compressible Navier-Stokes Equations," AIAA Paper 2003-3987, June 2003.

${ }^{28}$ Bradshaw, P., Launder, B. E., and Lumley, J. L., “Collaborative Testing of Turbulence Models," Journal of Fluids Engineering, Vol. 118, June 1996, pp. 243-247.

29"The 1980-81 AFOSR-HTTM Stanford Conference on Complex Turbulent Flows: A Comparison of Computation and Experiment," Volumes I, II, and III, edited by S. J. Kline, B. J. Cantwell, and G. M. Lilley, Stanford University, 1981.

${ }^{30}$ Eca, L., Hoekstra, M., and Roache, P. J., "Verification of Calculations: an Overview of the Lisbon Workshop," AIAA Paper 2005-4728, June 2005.

${ }^{31}$ Eca, L., Hoekstra, M., and Roache, P. J., "Verification of Calculations: an Overview of the 2nd Lisbon Workshop," AIAA Paper 2007-4089, June 2007.

${ }^{32}$ Eca, L., Hoekstra, M., Roache, P. J., and Coleman, H. W., "Code Verification, Solution Verification and Validation: an Overview of the 3rd Lisbon Workshop," AIAA Paper 2009-3647, June 2009.

${ }^{33}$ Eca, L., Hoekstra, M., Hay, A., and Pelletier, D., "On the Construction of Manufactured Solutions for One and Two-Equation Eddy-Viscosity Models," Int. J. Numer. Meth. Fluids, Vol. 54, 2006, pp. 119-154.

${ }^{34}$ Eca, L., Hoekstra, M., Hay, A., and Pelletier, D., "A Manufactured Solution for a Two-Dimensional Steady Wall-Bounded Incompressible Turbulent Flow," Int. J. Computational Fluid Dynamics, Vol. 21, Nos. 3-4, pp. 175-188.

${ }^{35}$ Durbin, P. A., "Separated Flow Computations with the $k-\varepsilon-v^{2}$ Model," AIAA Journal, Vol. 33, No. 4, April 1995, pp. $659-664$.

${ }^{36}$ Olsen, M. E., Lillard, R. P., and Coakley, T. J., "The Lag Model Applied to High Speed Flows,” AIAA Paper 2005-101, January 2005.

${ }^{37}$ Robinson, D. F. and Hassan, H. A., "Further Development of the $k$ - $\zeta$ (Enstrophy) Turbulence Closure Model," AIAA Journal, Vol. 36, No. 10, 1998, pp. 1825-1833. 
${ }^{38}$ Smith, B. R., "Prediction of Hypersonic Shock-Wave / Turbulent Boundary-Layer Interactions," Journal of Spacecraft and Rockets, Vol. 33, No. 5, Sept.-Oct. 1996, pp. 614-619.

${ }^{39}$ Jones, W. P. and Launder, B. E., "The Calculation of Low-Reynolds-Number Phenomena with a Two-Equation Model of Turbulence," Int. J. Heat Mass Transfer, Vol. 16, 1973, pp. 1119-1130.

${ }^{40}$ Craft, T. J., Launder, B. E., and Suga, K., "Development and Application of a Cubic Eddy-Viscosity Model of Turbulence," Int. J. Heat and Fluid Flow, Vol. 17, 1996, pp. 108-115.

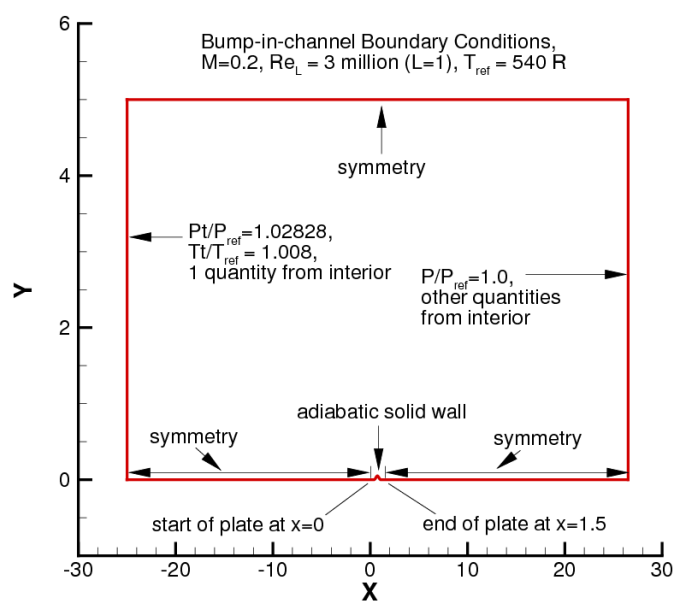

(a) farfield

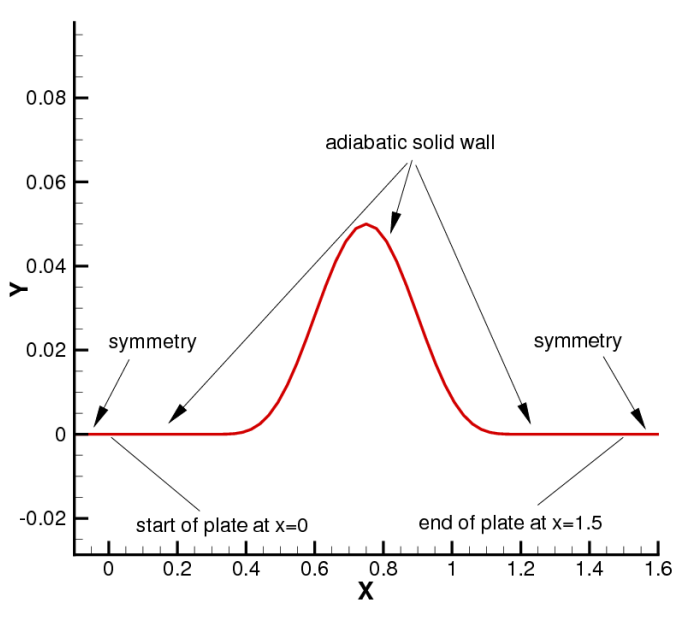

(b) close-up of bump

Figure 1. Boundary conditions for 2-D bump-in-channel verification case. 


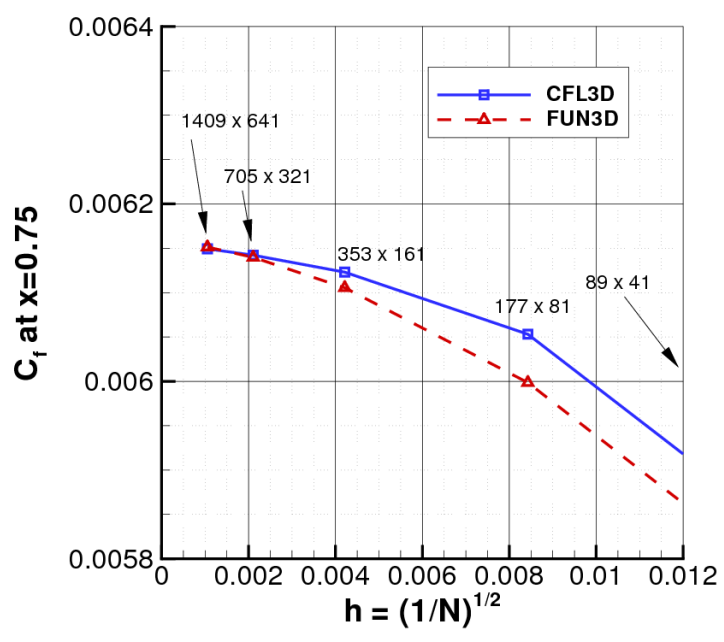

(a) $C_{f}$ as function of grid density at $x=0.75$

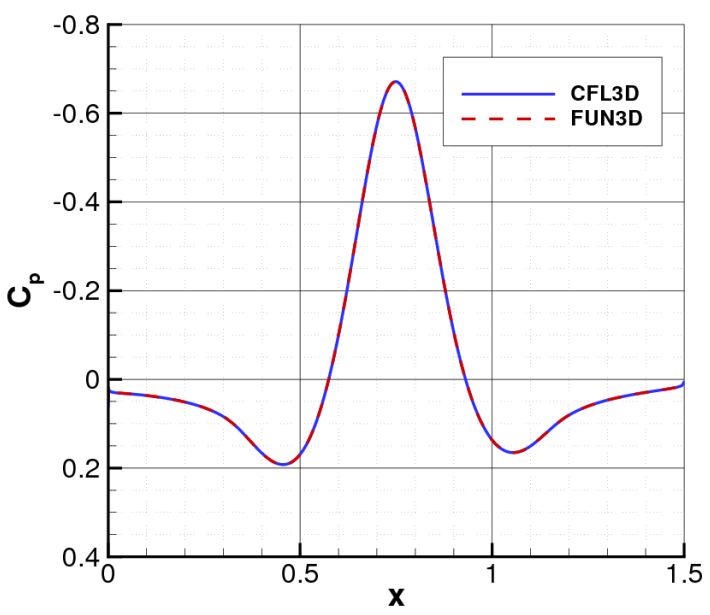

(c) $C_{p}$ on finest grid $(1409 \times 641)$

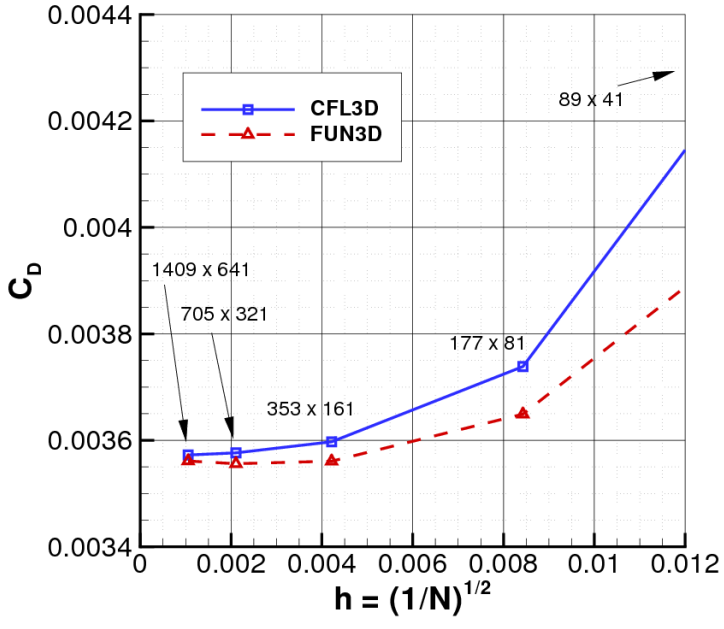

(b) $C_{d}$ as function of grid density

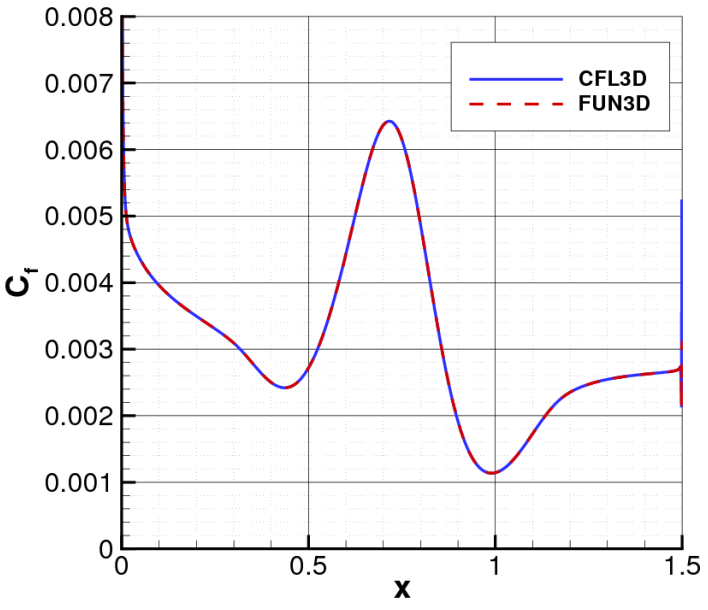

(d) $C_{f}$ on finest grid

Figure 2. Spalart-Allmaras (SA) model results using two different CFD codes for 2-D bump-in-channel verification case. 


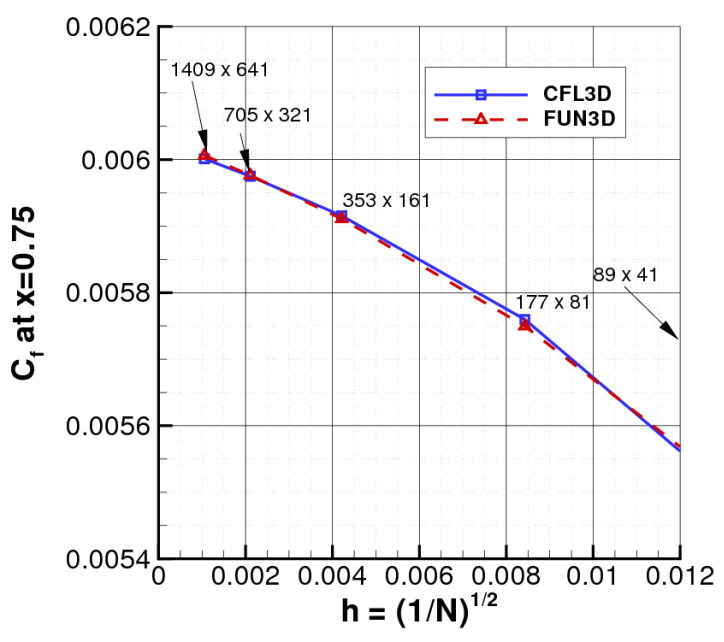

(a) $C_{f}$ as function of grid density at $x=0.75$

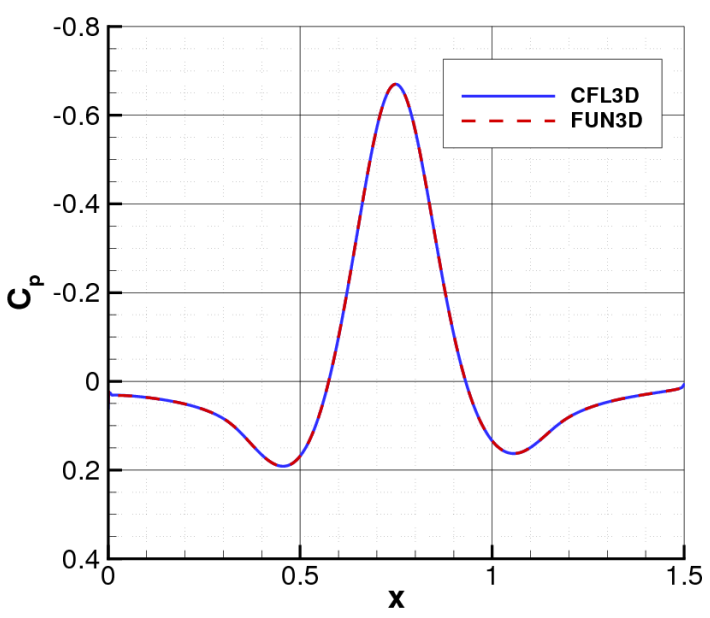

(c) $C_{p}$ on finest grid $(1409 \times 641)$

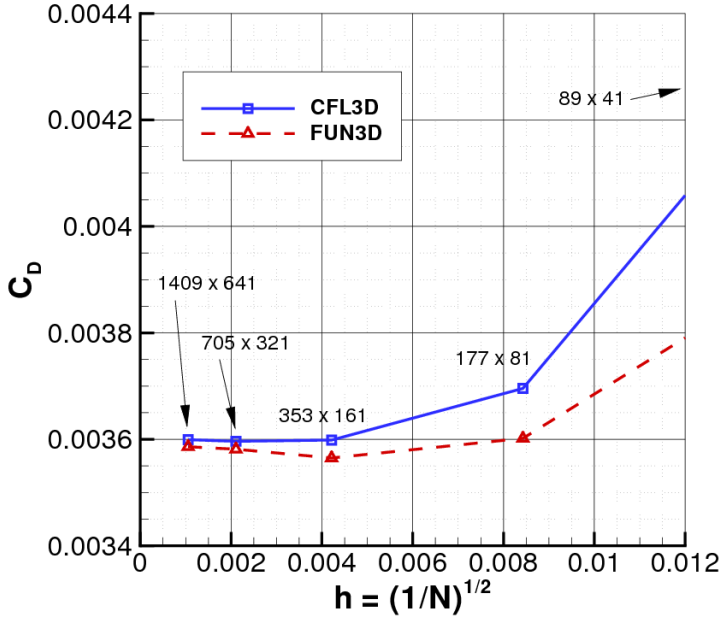

(b) $C_{d}$ as function of grid density

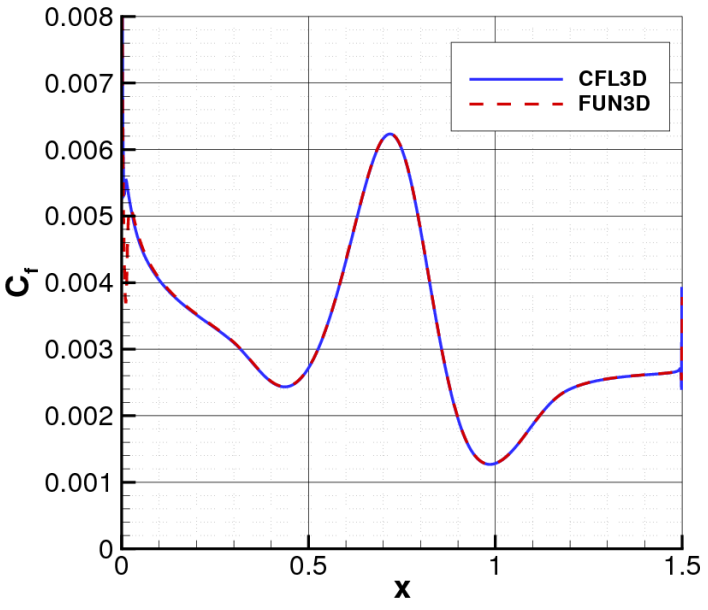

(d) $C_{f}$ on finest grid

Figure 3. Menter $k$ - $\omega$ SST (SST-V) model results using two different CFD codes for 2-D bump-in-channel verification case. 


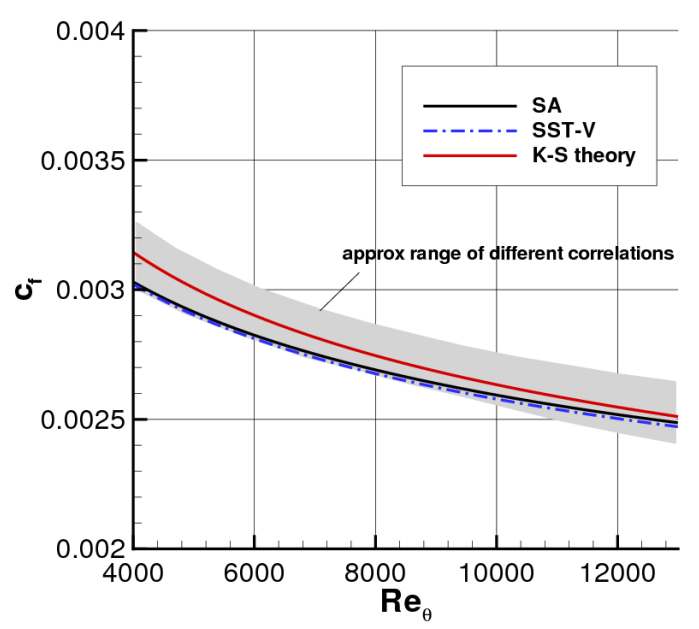

(a) skin friction

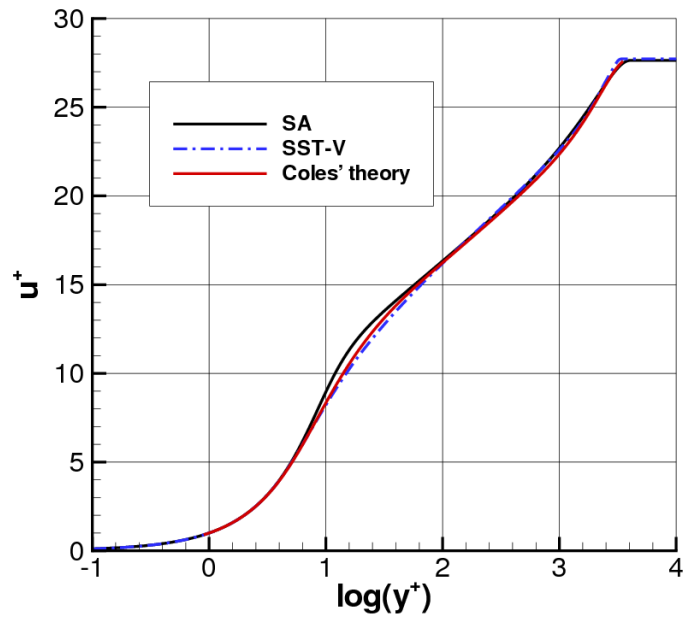

(b) velocity profile at $R e_{\theta}=10,000$ in inner wall variables

Figure 4. 2-D incompressible flat plate CFL3D results on $545 \times 385$ grid for SA and SST-V models compared to theory.

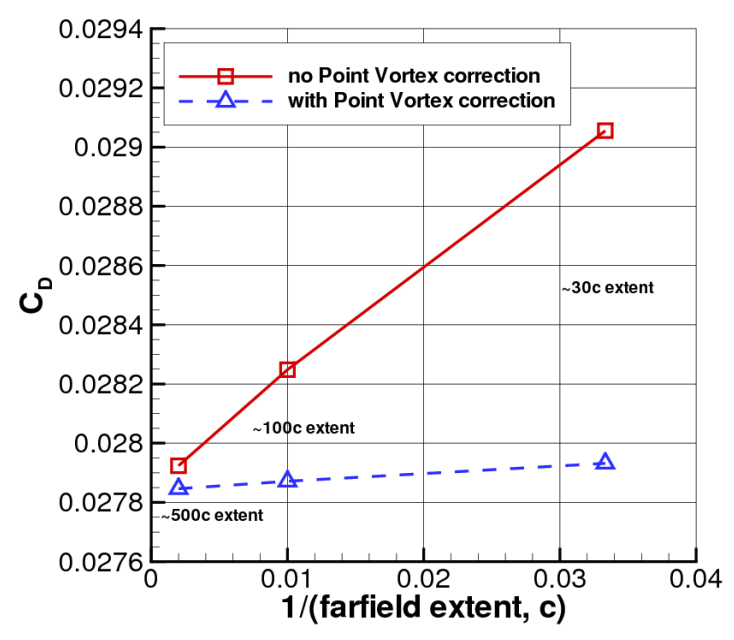

(a) effect of farfield grid extent on $C_{d}$ (using $225 \times 65$ base grid)

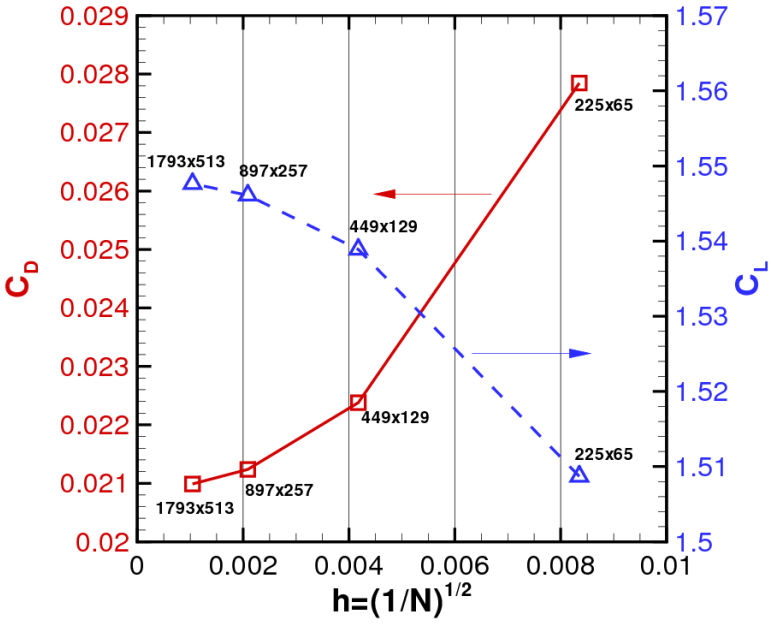

(b) grid density study

Figure 5. NACA 0012 studies, $M=0.15, \mathrm{Re}=6$ million, $\alpha=15^{\circ}$ using CFL3D and SA model. 


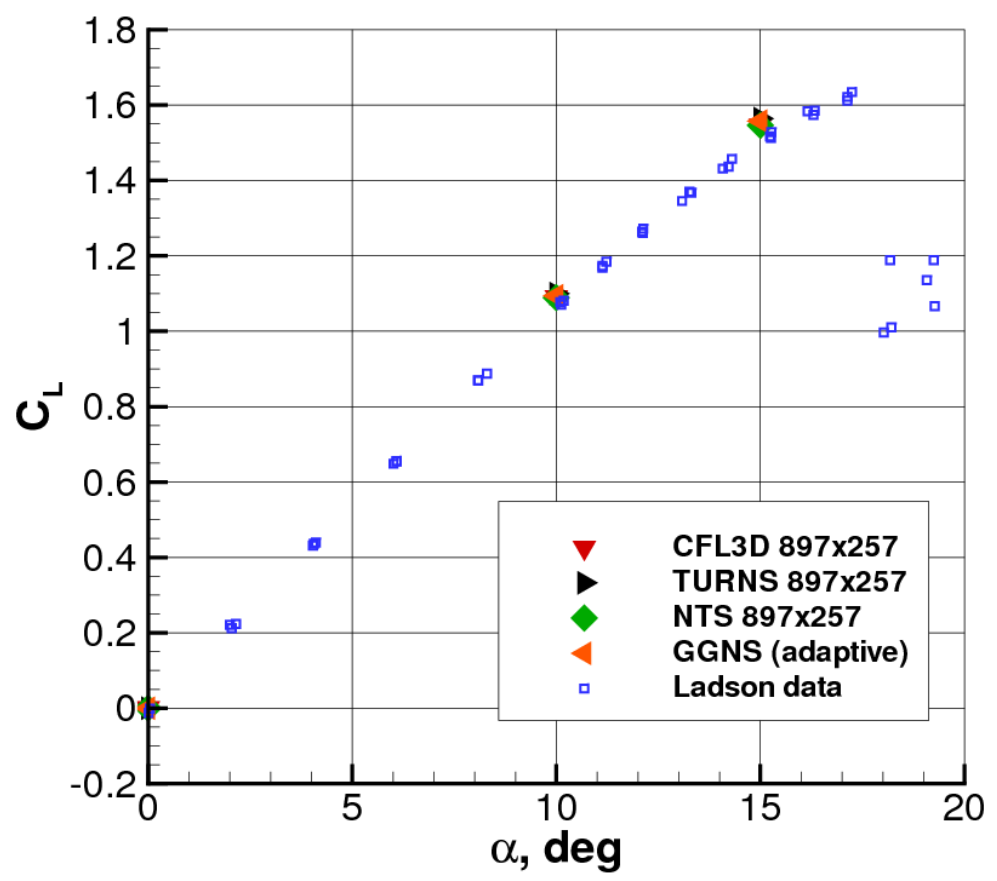

(a) lift coefficient vs. angle of attack

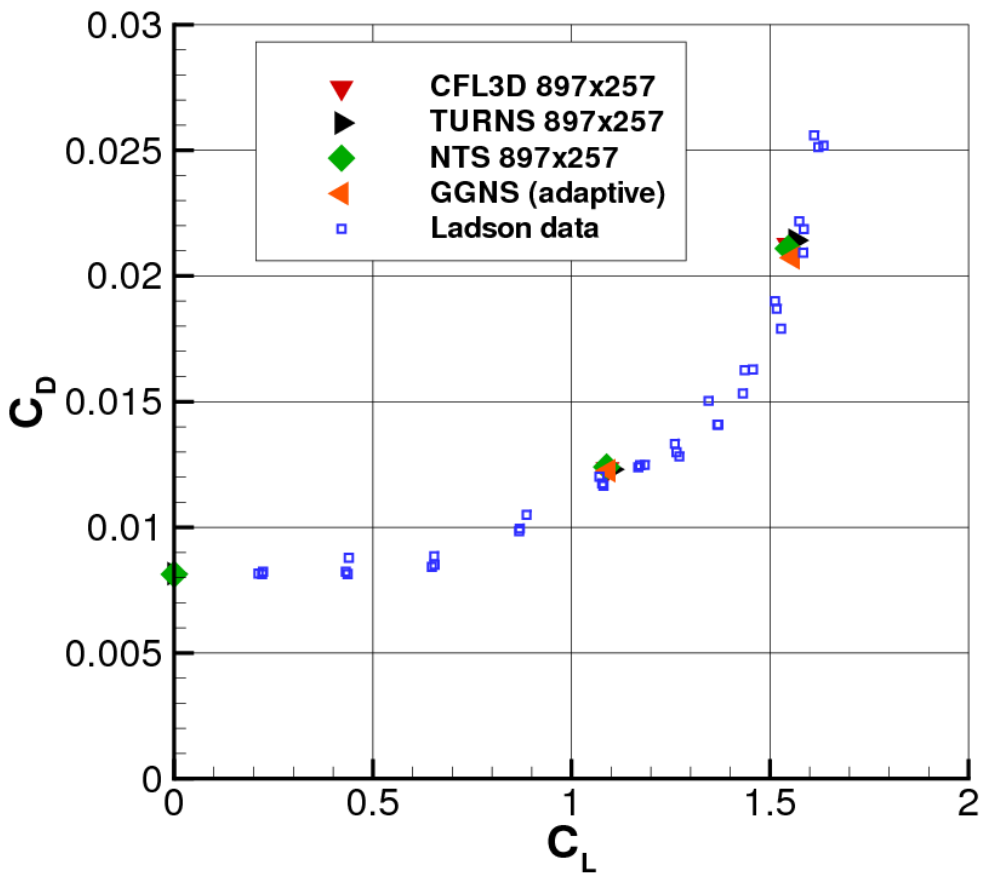

(b) drag coefficient vs. lift coefficient

Figure 6. Forces for NACA 0012 airfoil on $897 \times 257$ grid, SA model. 


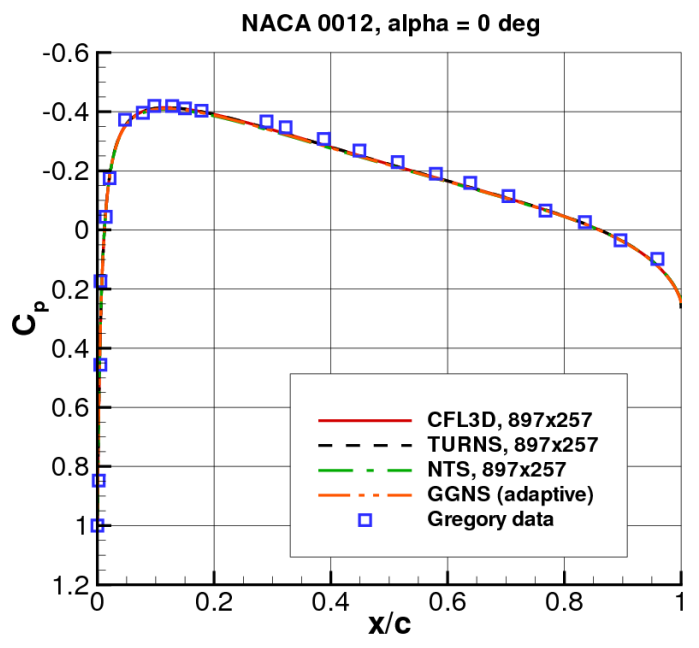

(a) $C_{p}, \alpha=0^{\circ}$

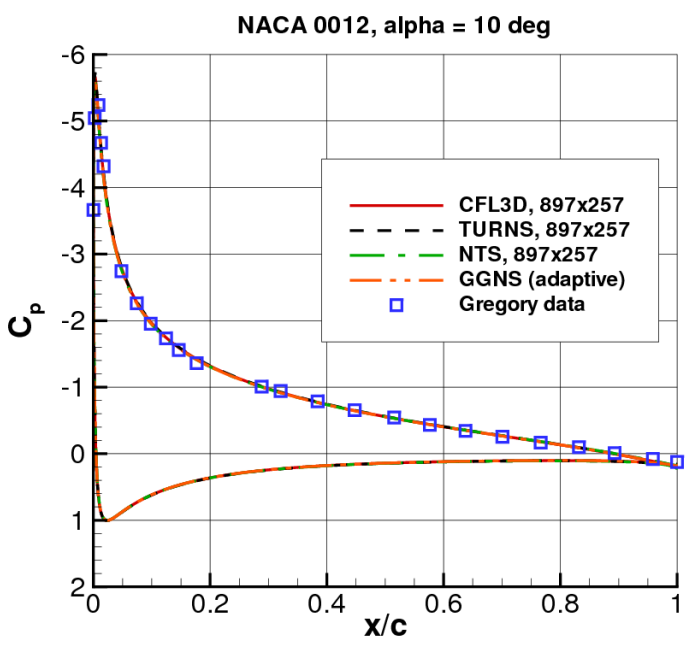

(c) $C_{p}, \alpha=10^{\circ}$

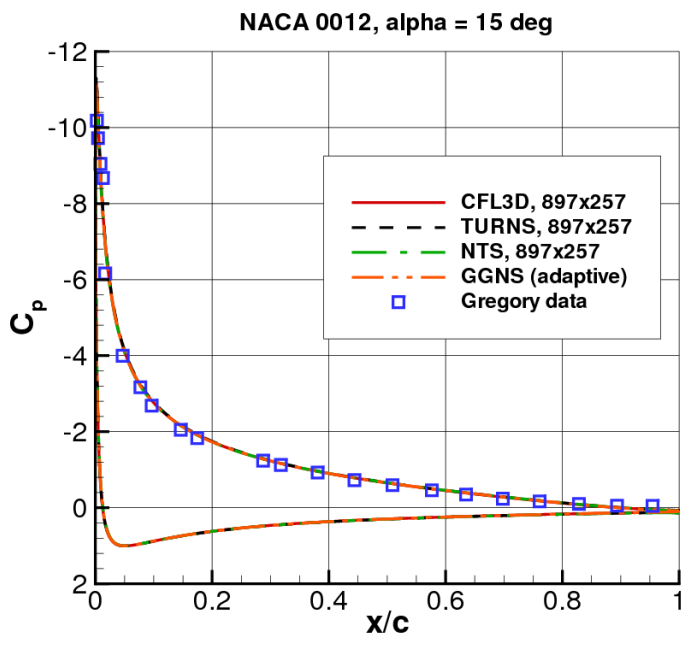

(e) $C_{p}, \alpha=15^{\circ}$

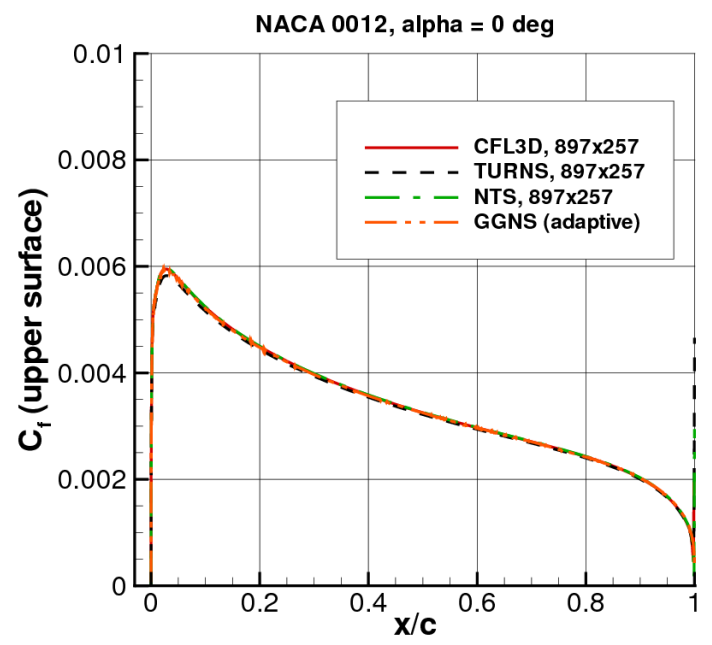

(b) upper surface $C_{f}, \alpha=0^{\circ}$

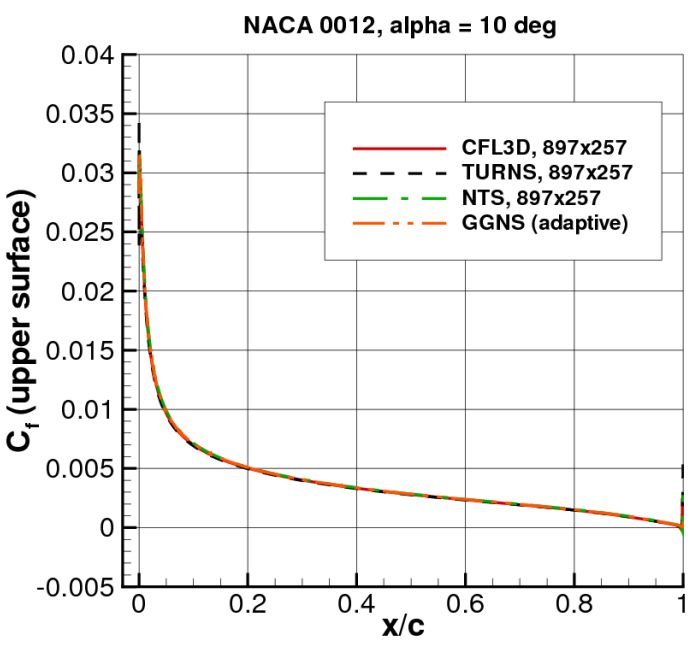

(d) upper surface $C_{f}, \alpha=10^{\circ}$

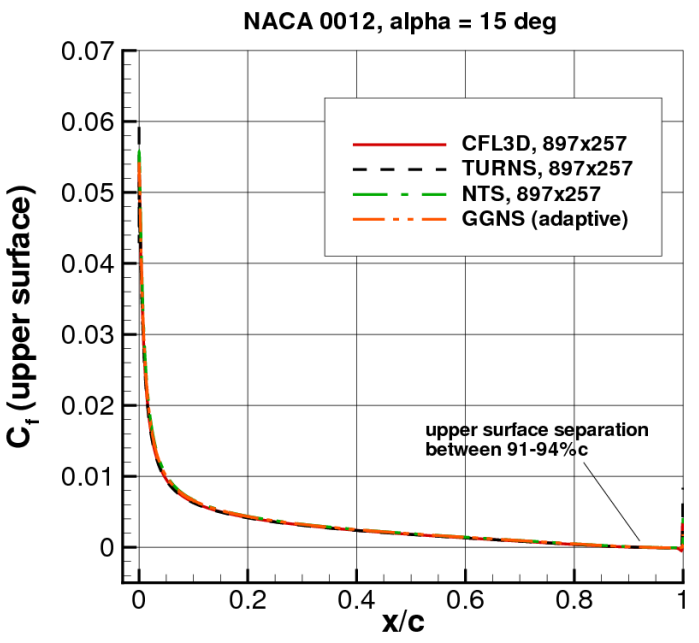

(f) upper surface $C_{f}, \alpha=15^{\circ}$

Figure 7. Surface results for NACA 0012 airfoil on $897 \times 257$ grid, SA model; pressure coefficients in left column, upper surface skin friction coefficients in right column. 